anonymised. The reports should cover the general areas of activity audited, the overall conclusions and recommendations made, and plans for action or procedural changes, the necessity for which has been revealed by the audit ( $\mathrm{HC}(91) 2$ para 8$)$. There should also be a record of when a review of the results of the changes should be made and the proposed methods of review. These reports will normally be submitted to management through the medical Audit Committee.

These interim guidelines have been endorsed by the Chief Medical Officer of the Department of Health.

The conference is grateful to Dr Peter Beck and to Dr Anthony Hopkins for their help in preparing this guidance.

\title{
Winter Quarterly Meeting, 1992
}

The Winter Quarterly Meeting was held at the Royal Institute of British Architects, London on 21 and 22 January 1992 under the Presidency of Professor A. C. P. Sims.

\section{Business Meeting}

The business meeting was held on 22 January, attended by 24 Members of the College.

\section{Minutes}

The minutes of the Autumn Quarterly Meeting held at Kensington Town Hall, London on 23 October 1991 were approved and signed.

\section{Registrar's report}

The Confidential Enquiry into 'Homicide and Suicide in Mentally Ill Persons' has now found premises at No.16 Belgrave Square and a Director, Dr Bill Boyd, currently Treasurer of the College. The Department of Health is providing the financial backing.
The College has responded to the initial reports of the three advisory groups to the Reed Committee on Mentally Abnormal Offenders. There will be further deliberations of this Committee with a strong input of general as well as forensic psychiatrists.

The division of purchasers and providers has now pervaded many of the reports coming from the Sections and Working Groups of the College. A working partly jointly established with the Faculty of Public Health is endeavouring to provide members of the College with some guidelines to assist them to maintain high standards of clinical practice under these new arrangements.

Two new special interest groups will be formally established at our Spring Meeting in Dundee. They are the special interest group for transcultural psychiatry and the special interest group for management issues.

There is now some discussion about the frequency of meetings. It is suggested that overall attendance would be highest if there were only two meetings the Annual Meeting and a second early in the year. The meetings could be longer and have more parallel sessions and we welcome comments from all the members about this.

Professor Ann Gath

\section{Discussion paper on frequency of College meetings}

It has been suggested that the format of the College's Quarterly Scientific Meetings should change. This paper puts forward the proposal that there should be two large scientific meetings per year, one of which might be held in London and the other might rotate and be held where suitable conference facilities are available.

Members and speakers are experiencing greater problems in claiming travelling expenses and study leave in order to attend College meetings. While attendance at Section meetings is growing, the attendance at some Divisional meetings is decreasing. The number of delegates at the Autumn and Annual meetings continues to grow each year while attendance at the Winter and Spring meetings is variable. It is anticipated, as at the recent Annual Meeting, that if the College meetings are limited to two per year then attendance overall will increase.

The suggestion to restrict the College meetings has come, not only from many Chairmen of Sections and Divisions, but also from members of the Programmes and Meetings Committees. A paper 